\section{Commentary: Taking the next step in cardiopulmonary bypass management}

\author{
Andrew J. Lodge, MD, ${ }^{a}$ and \\ Travis Siffring, MS, CCP, FPP
}

Cardiopulmonary bypass (CPB) is a system familiar to us all. Many of us use it virtually on a daily basis while we are going about the business of performing our jobs as surgeons. Although incredible advances in perfusion science have been made during the past several decades, it has struck me in recent years that despite the advances in technology of all sorts, our current heart-lung machines still seem relatively large, complicated masses of machinery and tubing that occupy a relatively large footprint in the cardiac operating room. I think back to the early CPB machines, such as the one from our institution pictured in Life Magazine back in 1957 (Figure 1) and wonder why we have not come further. When I compare the (admittedly much simpler) extracorporeal membrane oxygenation circuits that we use today that are portable and have built-in on-board monitoring, it makes me wonder why we have not come further with making a simpler and more compact heart-lung machine.

In addition to the perfusion equipment itself, a critical aspect of applying CPB technology is monitoring the circuit and the patient. In the report by Condello and colleagues ${ }^{1}$ in this issue of the JTCVS Techniques, different strategies for the management of CPB using different target parameters are compared. In 1 group ("control"), the cardiac index

From the a Division of Cardiovascular and Thoracic Surgery, Department of Surgery, Pediatric and Congenital Heart Center, and ${ }^{\mathrm{b}}$ Department of Perfusion Services, Duke University Medical Center, Durham, NC.

Disclosures: The authors reported no conflicts of interest.

The Journal policy requires editors and reviewers to disclose conflicts of interest and to decline handling or reviewing manuscripts for which they may have a conflict of interest. The editors and reviewers of this article have no conflicts of interest.

Received for publication March 30, 2020; revisions received March 30, 2020; accepted for publication March 31, 2020; available ahead of print April 11, 2020.

Address for reprints: Andrew J. Lodge, MD, Division of Cardiovascular and Thoracic Surgery, Department of Surgery, Pediatric and Congenital Heart Center, Duke University Medical Center, Box 3340, Durham, NC 27710 (E-mail: andrew.lodge@ duke.edu).

JTCVS Techniques 2020;2:100-1

2666-2507

Copyright $(2020$ The Authors. Published by Elsevier Inc. on behalf of The American Association for Thoracic Surgery. This is an open access article under the CC BY-NCND license (http://creativecommons.org/licenses/by-nc-nd/4.0/).

https://doi.org/10.1016/j.xjtc.2020.03.034

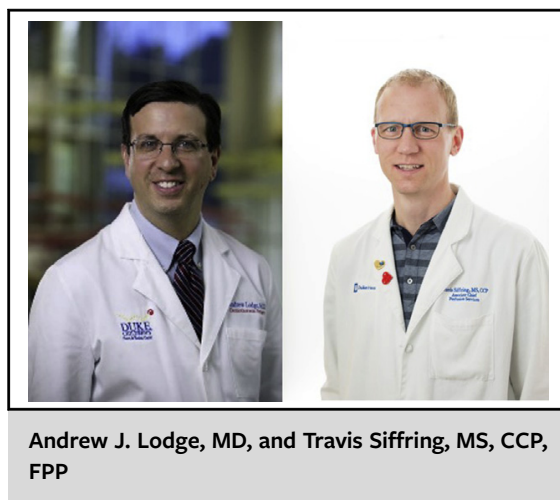

CENTRAL MESSAGE

Cardiopulmonary bypass technology continues to advance. More sophisticated monitoring strategies could be beneficial in improving the outcomes of patients for whom open heart surgery is necessary.

was adjusted according to a set mixed venous oxygen saturation $\left(\mathrm{SvO}_{2}\right)$ target. In contrast, in the other ("study") group, the indexed oxygen delivery $\left(\mathrm{DO}_{2} \mathrm{i}\right)$ was adjusted according to a target indexed oxygen extraction ratio $\left(\mathrm{O}_{2} \mathrm{ERi}\right)$. The latter strategy is somewhat more sophisticated and accounts for more variables. The findings of their study included less elevated lactate levels and glucose levels in the group managed with $\mathrm{DO}_{2} \mathrm{i}$ and $\mathrm{O}_{2} \mathrm{ERi}{ }^{1}$ It has been suggested that less elevated lactate levels can lead to lower postoperative creatinine levels and shorter mechanical ventilation time and intensive care unit lengths of stay. However, such differences between the 2 groups were not detected in their study.

Some of the limitations of the study include some variables for which there was no control, such as the inclusion of both open and closed circuits and the use of both central and peripheral cannulation. Importantly, the study used a consecutive patient series in which the control group represented an earlier period than the study group. ${ }^{1}$ This calls into question whether an era effect could have been involved because variables other than the CPB management strategy could have changed over time and affected the observations.

Although not all groups, especially in North America, have access to, or currently use, continuous $\mathrm{DO}_{2}$ during $\mathrm{CPB}$, its use could have advantages because $\mathrm{SvO}_{2}$ might 


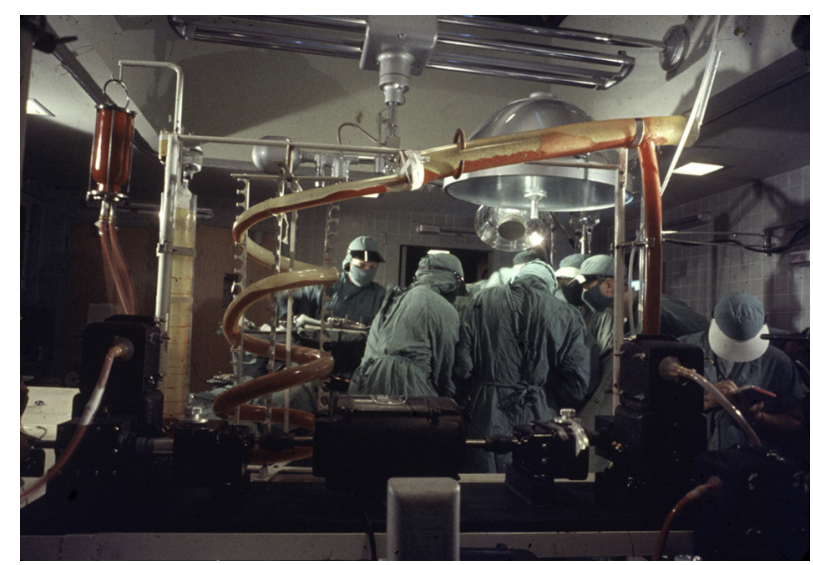

FIGURE 1. Cardiac surgical procedure at Duke University Medical Center in 1956 using large cardiopulmonary bypass apparatus as shown in Life Magazine in 1957.

be less sensitive to changes in various tissue beds. The most common correction for a lower $\mathrm{SvO}_{2}$ and, presumably, for a higher $\mathrm{O}_{2} \mathrm{ERi}$, would be to increase the overall CPB flow. Indeed, in the study by Condello et al, ${ }^{1}$ the nadir cardiac index on CPB was $2.6 \mathrm{~L} / \mathrm{min} / \mathrm{m}^{2}$ compared with $2.4 \mathrm{~L} / \mathrm{min} / \mathrm{m}^{2}$ in the control group, which was significantly different. Because the $\mathrm{DO}_{2} \mathrm{i}$ and $\mathrm{O}_{2}$ ERi incorporate more variables, it could have led the perfusionists to increase the pump flow in response to changes that were not observed with simple $\mathrm{SvO}_{2}$ monitoring. In addition, in the patients in the study group, if an increase in pump flow alone did not improve the $\mathrm{O}_{2} \mathrm{ERi}$, other variables contributing to oxygen delivery could have been modified.

In conclusion, the findings from their study make intuitive sense and corroborate the observation that many investigators in surgery and critical care have reported about oxygen delivery and consumption dynamics in patients. ${ }^{2-4}$ Should these findings be validated in a contemporaneous prospective or even randomized studies, it should lead to a justification for more widespread use of more contemporary sophisticated monitoring, which might, in turn, lead to improved patient outcomes.

\section{References}

1. Condello I, Santarpino G, Nasso G, Moscarelli M, Fiore F, Speziale G. Associations between oxygen delivery and cardiac index with hyperlactatemia during cardiopulmonary bypass. J Thorac Cardiovasc Surg Tech. 2020;2: 92-9.

2. Balzer F, Sander M, Simon M, Spies C, Habicher M, Treskatsch S, et al. High central venous saturation after cardiac surgery is associated with increased organ failure and long-term mortality: an observational cross-sectional study. Crit Care. 2015;19:168.

3. Kapoor PM, Magoon R, Rawat RS, Mehta Y, Taneja S, Ravi R, et al. Goal-directed therapy improves the outcome of high-risk cardiac patients undergoing off-pump coronary artery bypass. Ann Card Anaesth. 2017;20:83-9.

4. Futterman C, Salvin JW, McManus M, Lowry AW, Baronov D, Almodovar MC, et al. Inadequate oxygen delivery index dose is associated with cardiac arrest risk in neonates following cardiopulmonary bypass surgery. Resuscitation. 2019; 142:74-80. 